$06.1 ; 06.5$

\title{
Морфология и оптические свойства композитного материала на основе наночастиц золота и нестехиометрического оксида кремния
}

\author{
(C) А.О. Замчий ${ }^{1,2}$, С.В. Старинский ${ }^{1,2}$, Е.А. Баранов ${ }^{1}$ \\ ${ }^{1}$ Институт теплофизики им. С.С. Кутателадзе СО РАН, Новосибирск, Россия \\ ${ }^{2}$ Новосибирский государственный университет, Новосибирск, Россия \\ E-mail: zamchiy@gmail.com
}

Поступило в Редакцию 8 мая 2020г.

В окончательной редакции 19 мая 2020г.

Принято к публикации 19 мая 2020 г.

Впервые проведено исследование морфологии, структурных и оптических свойств композитного материала на основе наночастиц золота и тонкой пленки аморфного нестехиометрического оксида кремния $\left(a-\mathrm{SiO}_{x}\right.$, $x=1.8)$. На основе полученных результатов экспериментально показано, что слой $a-\mathrm{SiO}_{1.8}$ конформно покрывает наночастицы сферической формы. Аналитическая модель на базе теории Ми хорошо описывает полученные из эксперимента оптические свойства наночастиц золота и композитного материала в ультрафиолетовой области спектра, а также изменение амплитуды плазмонного пика при формировании композитного материала.

Ключевые слова: наночастицы золота, тонкие пленки, нестехиометрический оксид кремния, локализованный плазмонный резонанс, просвечивающая электронная микроскопия.

DOI: 10.21883/PJTF.2020.16.49855.18372

Наночастицы (НЧ) благородных металлов (золота, серебра и др.) проявляют выраженные плазмонные свойства в видимом диапазоне длин волн [1]. Зачастую практическое использование плазмонных НЧ предполагает их внедрение в диэлектрическую или полупроводниковую матрицу с функциональными и/или защитными свойствами [2,3]. Получаемые композитные материалы находят широкое применение при создании химических и биологических сенсоров [4], солнечных элементов [5], бактерицидных и противовирусных покрытий [6]. Наличие матрицы препятствует влиянию окружающей атмосферы на НЧ и предотвращает их деградацию, что способствует сохранению уникальных оптических свойств материала [3]. В то же время оптические свойства окружающей НЧ матрицы, а также общая морфология композитного материала оказывают существенное влияние на резонансную частоту локализованных плазмонов [2,3,7]. Следует отметить, что при получении композитного материала могут реализоваться необратимые процессы, приводящие к ухудшению и даже исчезновению его плазмонных свойств, диффузия НЧ из матрицы на ее поверхность, их агломерация, а также формирование соединений элементов материала матрицы и НЧ, вызванные, в частности, высокими температурами синтеза $[7,8]$.

Помимо эмпирических подходов по оптимизации процесса синтеза композитных материалов интерес исследователей также сфокусирован на усовершенствовании методов расчета для таких систем. Сегодня имеется множество аналитических [9] и расчетных работ [10], описывающих рассеяние падающего излучения на наномет- ровых объектах. Однако зачастую для полноценной верификации разрабатываемой теоретической модели получаемый объем экспериментальных данных о характеристиках изучаемого материала бывает недостаточным. В настоящей работе с помощью взаимодополняющих методик проведено исследование морфологии, структурных и оптических свойств композитного материала, представляющего собой $\mathrm{HЧ} \mathrm{Au}$ в матрице аморфного нестехиометрического оксида кремния $\left(a-\mathrm{SiO}_{x}\right)$. Отметим, что $a-\mathrm{SiO}_{x}$, с одной стороны, широко используется в полупроводниковой промышленности [11], а с другой стороны, является подходящим материалом для исследования влияния матрицы на свойства плазмонных НЧ. На основании полученных результатов сделаны выводы о различии между экспериментальными и расчетными плазмонными свойствами композитного материала.

НЧ Аu были получены методом импульсной лазерной абляции с использованием второй гармоники наносекундного $\mathrm{Nd}$ : YAG-лазера (длина волны $532 \mathrm{~nm}$, период $9 \mathrm{ns)}$ на подложках из кварца и монокристаллического кремния $(c-\mathrm{Si})$. Осаждение металла осуществлялось в атмосфере аргона при давлении $60 \mathrm{~Pa}$ и температуре подложки $500^{\circ} \mathrm{C}$. Далее $\mathrm{HЧ} \mathrm{Au}$ покрывались тонкой пленкой $a-\mathrm{SiO}_{x}(\sim 35 \mathrm{~nm})$ методом плазмохимического осаждения из газовой фазы из смеси моносилана и кислорода. Мощность высокочастотного (13.56 MHz) излучения и температура подложки в процессе синтеза составляли $50 \mathrm{~W}$ и $220^{\circ} \mathrm{C}$ соответственно.

На рис. 1 представлено изображение островковой пленки $\mathrm{Au}$ до осаждения $a-\mathrm{SiO}_{x}$, полученное методом сканирующей электронной микроскопии (СЭМ) на 


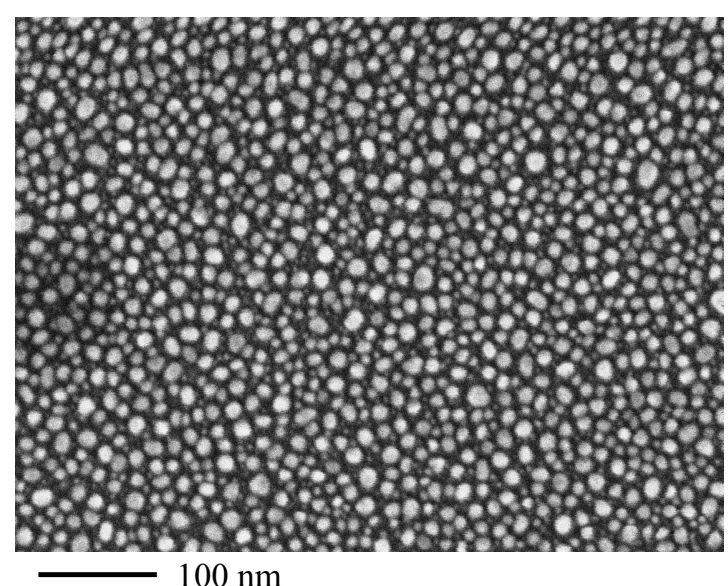

Рис. 1. СЭМ-изображение НЧ Аu на подложке из $c$-Si.

приборе JEOL JSM-6700F. Распределение частиц по размерам описывается бимодальной функцией. Размер мелкой популяции составляет несколько единиц нанометров, средний диаметр частиц крупной популяции около $12 \mathrm{~nm}$. Наблюдаемая морфология типична для высокотемпературного осаждения пленок золота методом импульсной лазерной абляции в фоновом газе. Бимодальная функция распределения НЧ обусловлена их ростом из двух различных видов зародышей. Первый тип образуется в результате столкновения блуждающих по поверхности осажденных атомов. Роль зародышей второго типа играют малые кластеры, образующиеся на этапе разлета лазерного факела [12].

На рис. 2, $a$ представлены спектры экстинкции НЧ $\mathrm{Au}$ на кварцевой подложке, пленки $a-\mathrm{SiO}_{x}$, а также композитного материала $\mathrm{HЧ} \mathrm{Au} / a-\mathrm{SiO}_{x}$, полученные с использованием спектрофотометра СФ-2000 („ЛОМО-Спектр“, Санкт-Петербург). Оптические характеристики НЧ $\mathrm{Au}$ определяются крупной популяцией частиц ввиду кубической зависимости сечения рассеяния от диаметра [1]. Положение плазмонного пика НЧ Аu составляет $621 \mathrm{~nm}$ и смещено в длинноволновую область спектра по сравнению с положением, полученным из расчета для изолированной сферической НЧ, которое составило $505 \mathrm{~nm}$. По-видимому, этот сдвиг обусловлен взаимополяризацией НЧ, поскольку плотность заполнения поверхности частицами составляет $45 \%$ (рис. 1). Таким образом, характерное расстояние между границами частиц крупной популяции составляет $\sim 10 \mathrm{~nm}$, что сопоставимо с пространственным масштабом локализованного плазмона. После осаждения тонкой пленки $a-\mathrm{SiO}_{x}$ в спектре происходит смещение положения резонансного пика в длинноволновую область. При этом увеличение экстинкции в ультрафиолетовой (УФ) области спектра главным образом определяется фундаментальным поглощением в $a-\mathrm{SiO}_{x}$, т.е. в данной области спектра влияние матрицы на оптические свойства НЧ Аu пренебрежимо мало. Методом спектральной эллипсометрии было установлено, что в видимой области спектра действительная часть показателя преломления $a-\mathrm{SiO}_{x}$ практически неизменна и равна 1.59 , при этом его мнимая часть отличается от нуля только в УФ-диапазоне излучения. Расчет показал, что смещение плазмонного пика изолированной НЧ в материале с подобными оптическими свойствами составляет $\sim 40 \mathrm{~nm}$, при этом в эксперименте наблюдается заметно меньший сдвиг $(\sim 15 \mathrm{~nm})$. Возможным объяснением такого смещения является уменьшение эффекта взаимополяризации НЧ из-за заполнения пространства между ними оптически плотным веществом. Тем не менее расчет хорошо описывает экспериментально полученные оптические свойства как для $\mathrm{HЧ} \mathrm{Au}$, так и для композитного материала в УФ-области спектра. При этом наличие слоя $a-\mathrm{SiO}_{x}$ приводит к одинаковому увеличению амплитуды плазмонного пика в экспериментальном и расчетном спектрах.

Сравнение ИК-фурье-спектров $a-\mathrm{SiO}_{x}$ и композитного материала $\mathrm{HЧ} \mathrm{Au} / a-\mathrm{SiO}_{x}$, полученных с использованием спектрометра Scimitar FTS 2000, показывает отсутствие влияния НЧ на состав и структурную сетку осаждае-
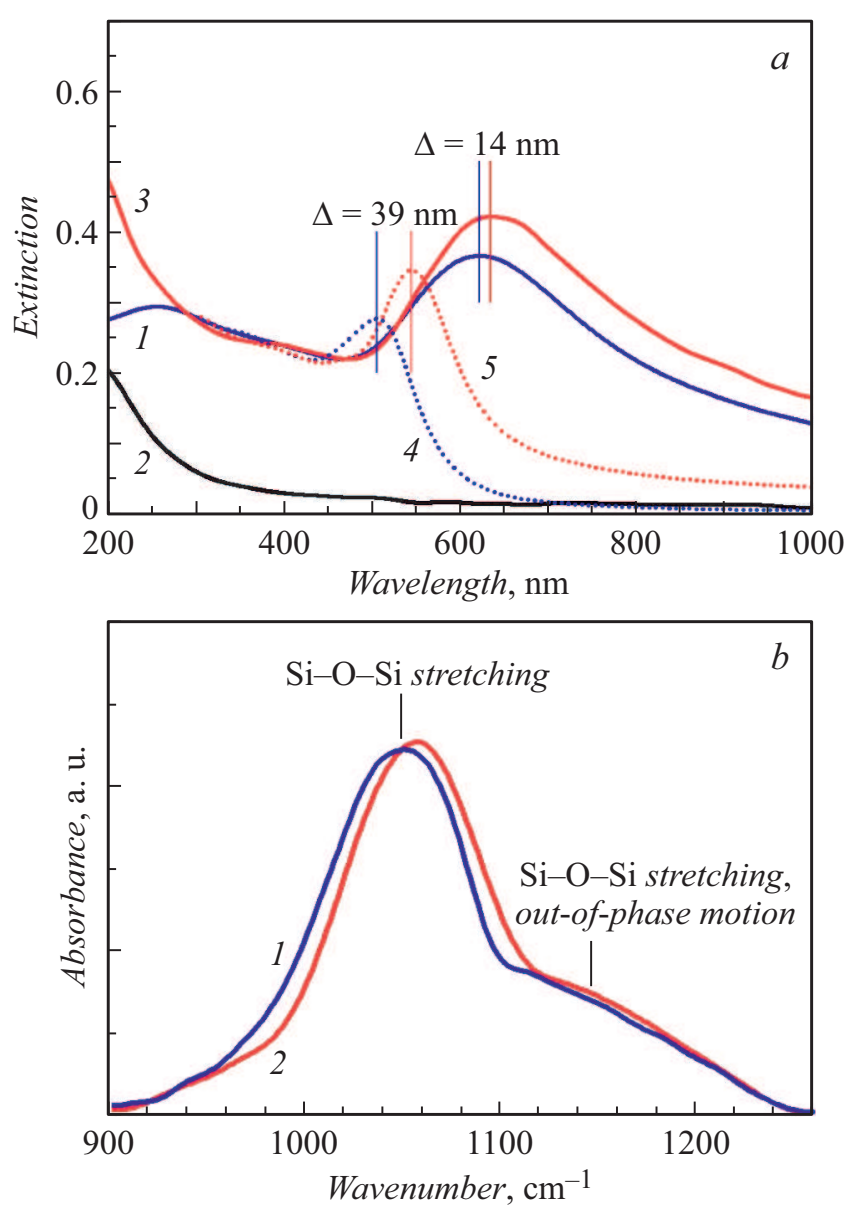

Рис. 2. $a$ - экспериментальные (сплошные линии) и расчетные (пунктирные линии) спектры экстинкции НЧ $\mathrm{Au}(1,4)$, $a-\mathrm{SiO}_{1.8}(2)$, а также композитного материала $\mathrm{HЧ} \mathrm{Au} / a-\mathrm{SiO}_{1.8}$ $(3,5) . b-$ спектральные зависимости оптической плотности $a-\mathrm{SiO}_{x}$ (1) и композитного материала $\mathrm{HЧ} \mathrm{Au} / a-\mathrm{SiO}_{x}$ (2) в инфракрасном диапазоне. 


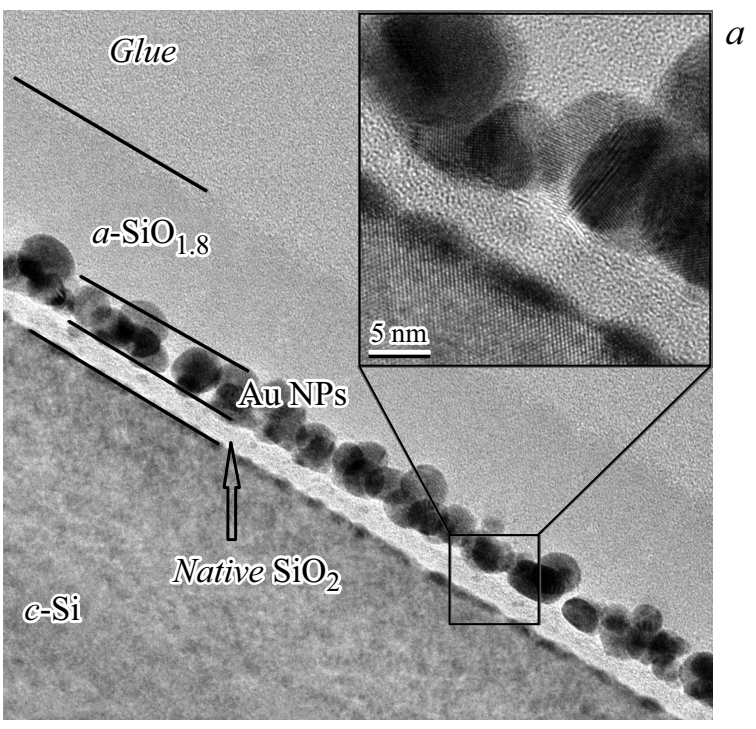

$20 \mathrm{~nm}$

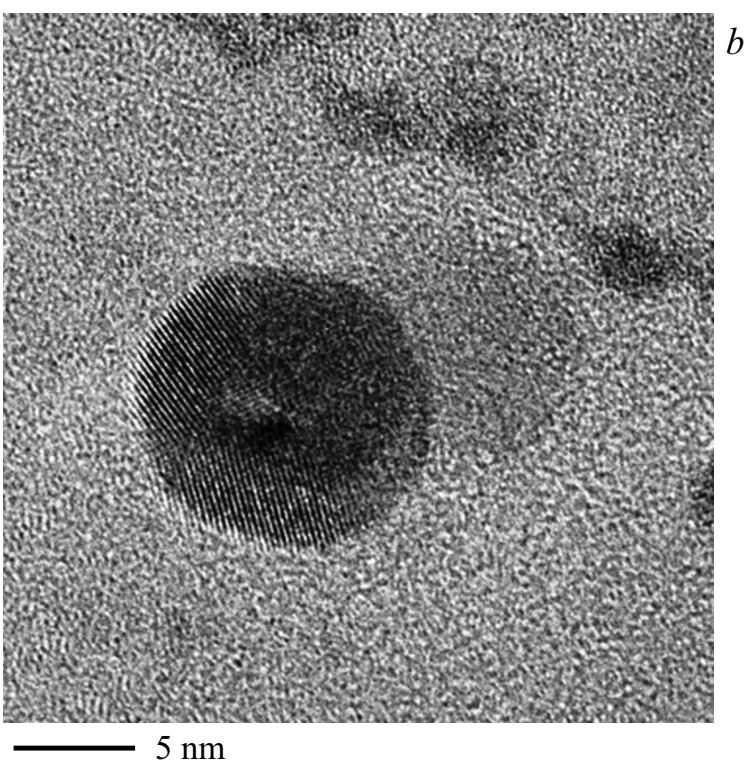

Рис. 3. $a-$ ПЭМ-изображение композитного материала НЧ $\mathrm{Au} / a-\mathrm{SiO}_{1.8}$. На вставке показано ВРПЭМ-изображение интерфейса подложка $c$-Si/естественный окисел. $b-$ ВРПЭМ-изображение отдельной НЧ $\mathrm{Au}$ в матрице $a-\mathrm{SiO}_{1.8}$.

мого нестехиометрического оксида кремния (рис. 2,b). Спектры содержат характерные для $a-\mathrm{SiO}_{x}$ синфазные (центр на $1052-1055 \mathrm{~cm}^{-1}$ ) и противофазные (центр на $\sim 1140 \mathrm{~cm}^{-1}$ ) моды колебания растяжения группы $\mathrm{Si}-\mathrm{O}-\mathrm{Si}$. Согласно положению центра синфазной моды, стехиометрический коэффициент $a-\mathrm{SiO}_{x}$ составил $1.8 \pm 0.2[11]$, что хорошо согласуется с результатами, полученными другими методами (энергодисперсионной рентгеновской спектроскопии, эллипсометрии и рентгеновской фотоэлектронной спектроскопии).

Анализ поперечного среза образца методом просвечивающей электронной микроскопии (ПЭМ), выполненный на микроскопе JEOL JEM-2200FS, позволил получить более детальное представление о его морфологии (рис. 3,a), поскольку хорошо известно, что несферичность НЧ металлов оказывает влияние на их оптические характеристики [9]. Средний размер $\mathrm{HЧ} \mathrm{Au}$ составил $\sim 10 \mathrm{~nm}$, что в совокупности с данными СЭМ $(12 \mathrm{~nm})$ позволяет сделать вывод о сферической форме НЧ. Также из снимка видно, что покрытие НЧ $\mathrm{Au}$ тонкой пленкой $a-\mathrm{SiO}_{1.8}$ равномерное, и это позволяет считать его сплошным при анализе оптических свойств. Методом ПЭМ высокого разрешения (ВРПЭМ) была исследована структура материала. Данные (рис. 3,b) указывают на то, что пленка $a-\mathrm{SiO}_{1.8}$ имеет аморфную структуру, в то время как НЧ содержат как аморфную, так и кристаллическую фазу. Такие частицы могут формироваться в результате коалесценции островков, образующихся в результате различных механизмов: зародыши кристаллических НЧ образуются в лазерном факеле, аморфных - в результате столкновения адатомов [12]. Известно, что наличие кристаллических граней может влиять на проводимость металла, а следовательно, частота колебания электронов проводимости, составляющих локализованный плазмон, может отличаться от данных, приводимых в литературе. Подобно тому как в [13] была введена поправка на частоту колебания электронов при столкновении с границей НЧ, необходимо также учитывать их рассеяние на границах раздела областей разных фаз и кристаллитов различной кристаллографической ориентации. Отметим, что, согласно ВРПЭМ-изображению (вставка к рис. 3,a), золото проникает под естественный окисел и образует аморфные эллипсоидные глобулы на границе его раздела с $c$ - $\mathrm{Si}$, что обусловлено взаиморастворимостью $c$-Si и $\mathrm{Au}$ при высоких температурах [14]. Однако мы полагаем, что этот эффект отсутствует при осаждении НЧ $\mathrm{Au}$ на кварцевую подложку при данной температуре синтеза.

В работе впервые проведено исследование морфологии, структурных и оптических свойств композитного материала на основе $\mathrm{HЧ} \mathrm{Au}$ и тонкой пленки $a-\mathrm{SiO}_{1.8}$. Сферичность формы НЧ $\mathrm{Au}$ подтверждена взаимодополняющими исследованиями, проведенными методами СЭМ и ПЭМ. ПЭМ-исследования показали конформность покрытия НЧ $\mathrm{Au}$ слоем $a-\mathrm{SiO}_{1.8}$. Классическая аналитическая модель на базе теории Ми хорошо описывает полученные из эксперимента оптические свойства НЧ $\mathrm{Au}$ и композитного материала в УФ-области спектра, а также изменение амплитуды плазмонного пика при формировании композитного материала.

\section{Благодарности}

Авторы благодарны Г.К. Кривякину за ПЭМ-исследования образцов.

\section{Финансирование работы}

Работа выполнена при поддержке гранта Российского научного фонда № 19-79-10143 (осаждение НЧ Аu и 
$a-\mathrm{SiO}_{x}$, анализ методами СЭМ и ПЭМ) и гранта Президента РФ МК-2404.2019.8 (исследование оптических свойств материалов, расчеты по теории Ми).

\section{Конфликт интересов}

Авторы заявляют, что у них нет конфликта интересов.

\section{Список литературы}

[1] Борен К., Хафмен Д. Поглощение и рассеяние света малыми частицами. М.: Мир, 1986. 664 с.

[2] Walters G., Parkin I.P. // J. Mater. Chem. 2009. V. 19. P. 574 590. DOI: $10.1039 / \mathrm{B} 809646 \mathrm{E}$

[3] Safonov A.I., Sulyaeva V.S., Timoshenko N.I., Kubrak K.V., Starinskiy S.V. // Phys. Lett. A. 2016. V. 380. P. 3919-3923. DOI: $10.1016 /$ j.physleta.2016.10.003

[4] Tinguely J.C., Sow I., Leiner C., Grand J., Hohenau A., Felidj N., Aubard J., Krenn J.R. // Bionanoscience. 2011. V. 1. P. 128-135. DOI: $10.1007 / \mathrm{s} 12668-011-0015-4$

[5] de Aberasturi D.J., Serrano-Montes A.B., Liz-Marzán L.M. // Adv. Opt. Mater. 2015. V. 3. P. 602-617. DOI: 10.1002 adom.201500053

[6] Rai M., Ingle A.P., Birla S., Yadav A., Dos Santos C.A. // Crit. Rev. Microbiol. 2015. V. 42. P. 696-719. DOI: $10.3109 / 1040841 X .2015 .1018131$

[7] Faraone G., Modi R., Marom S., Podestá A., Di Vece M. // Opt. Mater. 2018. V. 75. P. 204-210. https://doi.org/10.1016/j.optmat.2017.10.025

[8] Bedel L., Cayron C., Jouve M., Maury F. // Nanotechnology. 2012. V. 23. P. 015603. https://doi.org/10.1088/0957-4484/23/1/015603

[9] Davis T.J., Gómez D.E. // Rev. Mod. Phys. 2017. V. 89. P. 011003. DOI: 10.1103/RevModPhys.89.011003

[10] Axelevitch A., Apter B., Golan G. // Opt. Express. 2013. V. 21. P. 4126-4138. DOI: 10.1364/OE.21.004126

[11] Zamchiy A.O., Baranov E.A., Merkulova I.E., Khmel S.Y., Maximovskiy E.A. // J. Non. Cryst. Solids. 2019. V. 518. P. 4350. DOI: 10.1016/j.jnoncrysol.2019.05.015

[12] Starinskiy S.V., Sulyaeva V.S., Shukhov Y.G., Cherkov A.G., Timoshenko N.I., Bulgakov A.V., Safonov A.I. // J. Struct. Chem. 2017. V. 58. P. 1581-1587. DOI: $10.26902 / J S C 20170815$

[13] Kreibig U., Fragstein C. // Z. Phys. 1969. V. 224. P. 307-323. DOI: 10.1007/BF01393059

[14] Bhatta U.M., Dash J.K., Rath A., Satyam P.V. // Appl. Surf. Sci. 2009. V. 256. P. 567-571. DOI: 10.1016/j.apsusc.2009.08.054 